\title{
Smart Home Services for a Smart Grid
}

\author{
Young-Myoung Kim and Young-Woo Lee \\ KT (Korea Telecom) \\ Korea
}

\section{Introduction}

A smart grid is a next-generation intelligent power grid, created by grafting ICT (Information Communication Technology) onto the current grid, which allows power suppliers and consumers to communicate on a two-way basis in real-time and to improve energy efficiency. Current grids are based on a one-way communication structure where power is generated in plants (utilities) and consumed in homes or buildings. However, in a smart grid, energy delivery and consumption is optimized using a real-time power supply and consumption data based on a two-way interactive communication structure. Therefore, as illustrated in Figure 1, significant improvements are expected throughout the value chain from generation to consumption in a smart grid.

For example, at the generation stage, even unstable intermittent renewable energy sources like solar energy and wind energy can be connected to the grid and large-scale renewable plants can be established. In addition, consumers would be able to generate electricity by building solar or wind generation systems in their own home or building. At the transmission/substation/distribution stages, information on devices and electricity in the grid would be delivered in real time and reliable fault prediction, efficient outage management and automatic self-repair (self healing) would become possible, ensuring a supply of stable electricity.

The most significant change will take place in the consumers' (home/building) stage, where consumers will now be able to use or sell the electricity generated by distributed generation using an energy storage device. Consumers will also be able to buy electricity when the price ${ }^{1}$ is low and sell when the price is high. Consumers will then be able to participate in not only consumption, but also in generation and sales; they will be able to monitor the price of electricity and the information on their energy consumption in real time and change their consumption behavior accordingly.

However, in order to induce real participation from the consumer's side, HAN (Home Area Network) and home energy management systems have to be established first, and the service has to be designed to be user-friendly and based on consumers' values and needs.

In this study, we explored the perception of consumers and the value they experienced when using electricity at home, to identify their unmet needs and suggest a few new services.

1 Utilities are expected to turn to new pricing schemes that adjust the price of electricity based on consumption patterns. Utilities will curb consumption during peak periods when electricity is most expensive, and shift consumption to those times when it is less expensive. 
Afterwards, we carried out a survey to evaluate consumers' willingness to use our suggested services and lastly we made suggestions for a successful home service on a smart grid.

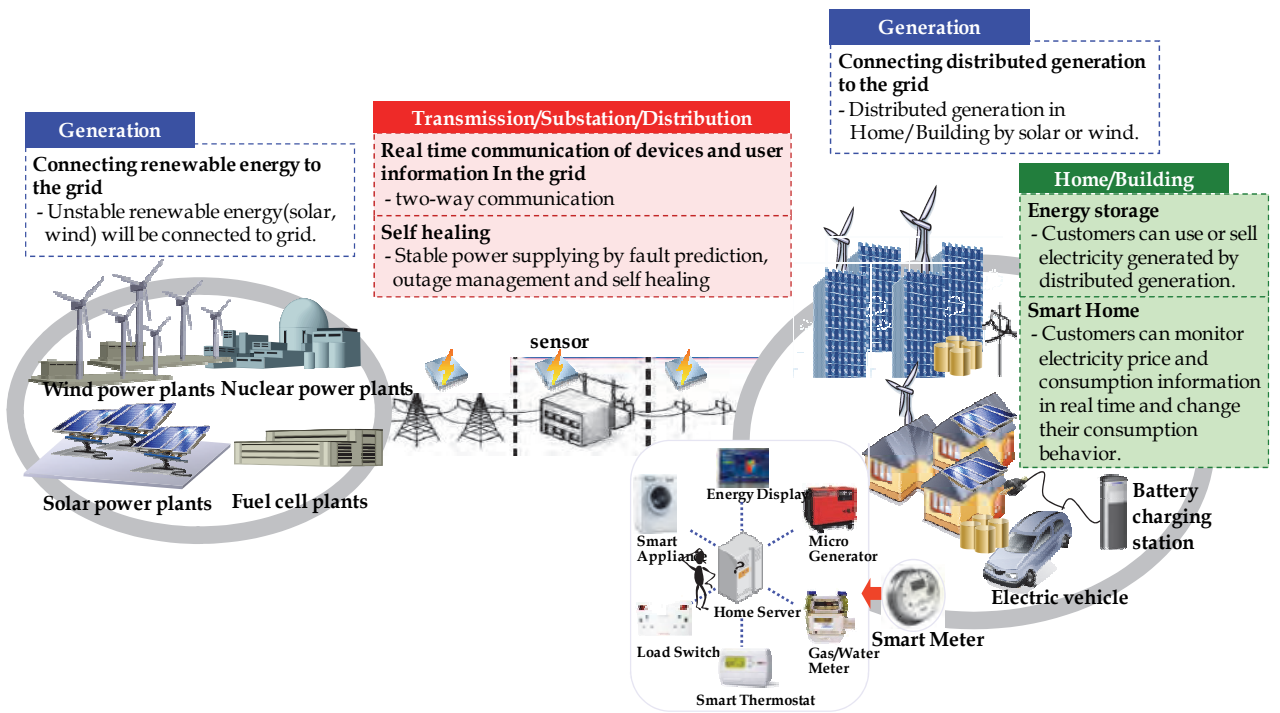

Fig. 1. The characteristic of a smart grid

\section{Outline of the survey}

There were two parts to our study. First, we explored the perception of consumers when using electricity at home and the values they would like to experience qualitatively using a HV (Home Visit) and a FGD (Focus Group Discussion). Afterwards, we carried out a quantitative survey to evaluate our consumers' willingness to use the suggested services. Both studies were carried out in Seoul, Korea.

The HV was performed according to a FLC (Family Life Cycle)-young couples with no children, families with children in K-5th grade, families with children in 6th-12th grade, families with children in college and old couples in an empty nest. The HV was performed in two stages; in the first stage, participants' electricity usage behavior was examined through observational studies and interviews and, in the second stage, changes in perception and attitude toward electricity usage were explored after the participants used electricity-saving products (an electricity inspector and an outlet timer) for some time.

The FGD was also carried out and the group was divided according to FLC in the same way as the above. However, since the participants in these groups were all housewives, we added one more group solely consisting of professional males. In the FGD, we completed a cognitive map to show the value of using electricity.

Lastly, a quantitative survey was carried out with 300 participants who reside in Seoul, Korea and use the electricity service. The sample was selected based on FLC and the survey was completed by interviewing the participants face-to-face. The main purpose of the survey was to identify the key values of using smart grid services and to test people's willingness to use our suggested services. 


\section{Customer perception and their values when using electricty}

Three main perceptions and values when using electricity were derived by using a cognitive map method. First, consumers perceived electricity as an 'indispensable necessity' that makes the use of home appliances possible. Second, consumers perceived electricity as a 'potential danger' that emits harmful electromagnetic waves, causes short circuits and electric shocks and suggested that they need to be safely protected from them. Lastly, consumers perceived electricity as a 'costly energy' that needs to be saved on the user's side and they want the use of electricity to be stress-free.

Figure 2 shows a cognitive map of how consumers perceive electricity as an 'indispensable necessity'. Consumers regarded electricity itself as an 'indispensable necessity', but that indispensability was often conceived as being connected to other home necessities such as a refrigerator, PC, air-conditioner or TV. Consumers displayed positive perceptions using words like warm, cool, bright and convenient toward electricity as it was deemed to be an indispensable necessity in their lives.

Customers also exhibited some negative perception towards electricity; they regarded electricity as a 'potential danger' that emits harmful electromagnetic waves and causes short circuits and electric shocks. As a result of the above, consumers expressed the need for safety during electricity usage. Figure 3 shows a cognitive map of how consumers perceive electricity as a 'potential danger'. In response to the various dangers that electricity usage poses, consumers constantly try to mitigate the threat by placing charcoal or plants known to absorb harmful electromagnetic waves in the house, dusting off outlets and unplugging unused appliances.

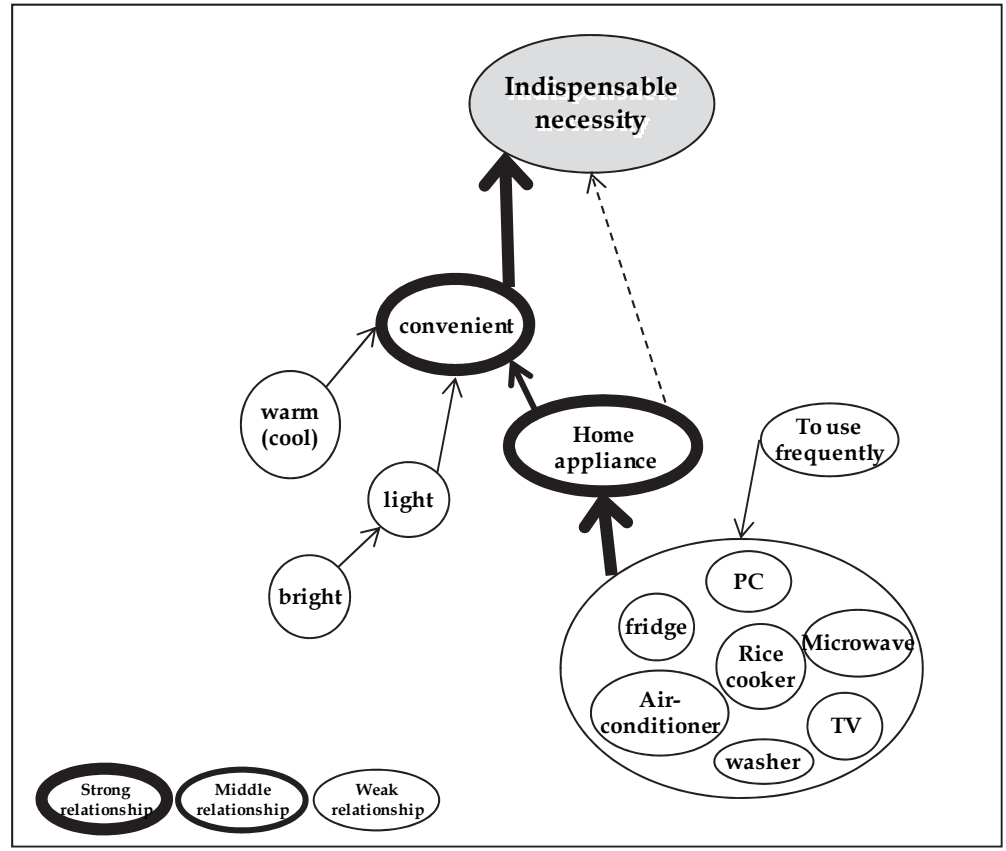

Fig. 2. Cognitive map (1) : Indispensable necessity 


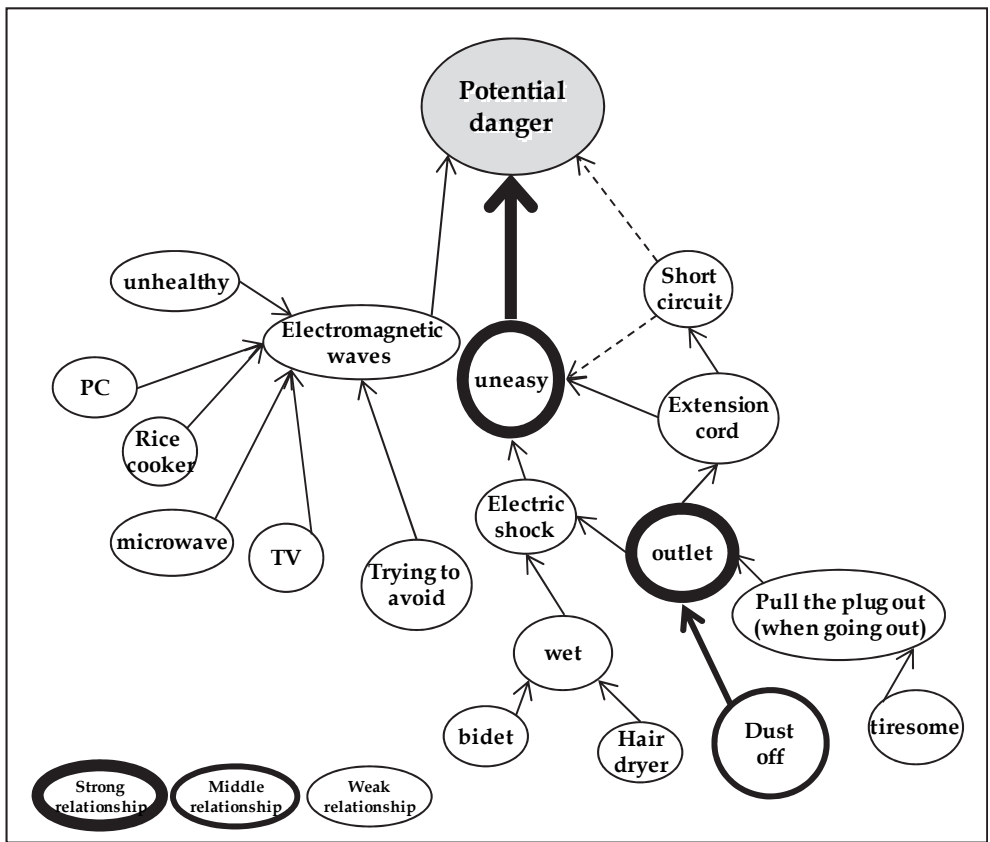

Fig. 3. Cognitive map (2) : Potential danger

Lastly, Figure 4 shows how consumers perceive electricity as a 'costly energy' that needs to be saved on the consumer side. In Korea, electricity rates are cumulative, which means consumers with a higher electricity consumption are charged at a higher rate. For example, the electricity price per kwh when consumers use over $500 \mathrm{kWh}$ is 11 times greater than the price per $\mathrm{kWh}$ when consumers use under $100 \mathrm{kWh}$. In this system, those who use more electricity are charged at a more expensive rate. Because of this system, most housewives in Korea are well aware of the cost of using electricity and feel the need to save money by wisely consuming electricity. Each housewife has their own way to save electricity usage but they are also feel tired of the pressure of being wise electricity consumer and are irked by the wasteful usage of other family members.

\section{Electricity usage behavior and unmet needs}

\subsection{Reducing electricity usage}

Home appliances can be grouped in three categories based on how frequently they are used; constant use, frequent use and occasional use. The first group is constantly used all throughout the day, thereby needing the power to be on all the time, like a refrigerator. The second group is used frequently throughout the day like a TV and PC and the last group is used occasionally like a hair dryer. Consumers show concerns about the power usage of appliances that are frequently used and try to turn off the power or unplug the cord in an attempt to save electricity usage. Their persistence in their attempts to reduce electricity usage depends on the nature of the appliance and its energy efficiency. For example, if an appliance consumes a lot of electricity (e.g., an air conditioner) or it is simple to unplug, they 


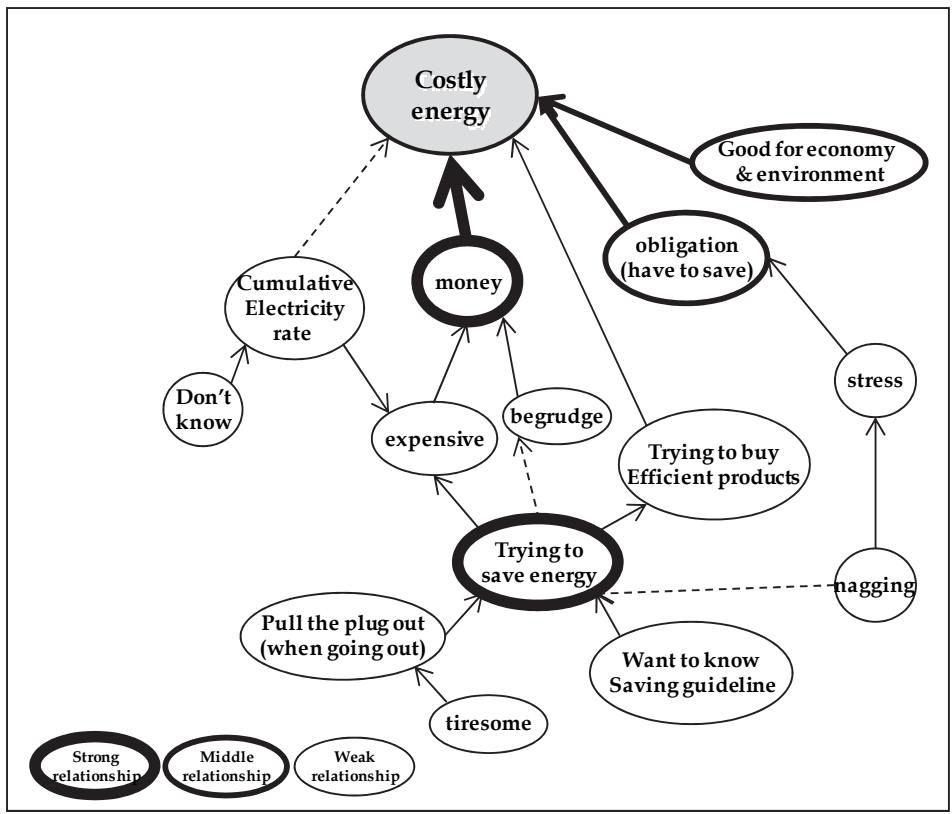

Fig. 4. Cognitive map (3) : Costly energy

just pull the plug out. However, sometimes laziness or fear of electric shocks, particularly from appliances like TVs or PCs that have many cables and complicated power arrangements, discourages consumers from unplugging them. Consumers often read their electronic bills thoroughly when the billed amount is higher than usual and compare their bill with that of their neighbors in order to find what caused a rise in the bill. Consumers try to reduce the use of appliances that use up much electricity and react sensitively toward reducing electricity usage. However, they confess to feeling tired from nagging other family members who react indifferently toward reducing electricity usage.

With regards to saving energy (reducing the use of electricity), most participants agreed with its importance but evaluated themselves as not adequately meeting the standard. 99\% of participants indicated that they agree or strongly agree with the importance of reducing electricity usage. However, only $48 \%$ agreed or strongly agreed that they are doing enough to reduce electricity usage, showing that many consumers feel like what they are doing is not enough in terms of saving energy.

Participants identified 'lack of functionality' in terms of controlling electricity usage, 'lack of information' when informing consumers of their usage behavior and 'lack of motivation' as the main reasons for their struggle to reduce electricity usage. They showed unmet needs in the following areas: a function that blocks the power leakage of an appliance when not in use, a function that informs the users on the level of electricity usage and the energyefficiency of each device, a function that notifies users of the cumulative rate ${ }^{2}$ of electricity usage and a motivator that pushes consumers to reduce their electricity usage.

2 The Korean electricity rate is a cumulative rate, which means the rate changes depending on the total amount of electricity used. So if there is an alarm system that helps consumers to know when their rate is about to move on to the next rate pricing category, it will significantly help them to save money. 


\begin{tabular}{|c|c|}
\hline Type of use & Behaviors \\
\hline Constant Use & $\begin{array}{l}\text { - } \quad \text { Refrigerator, telephone, water purifier, etc } \\
\text { - Switch is on all day } \\
\text { - } \quad \text { Do not unplug } \\
\text { - } \quad \text { Some are built-in devices } \\
\text { - Consumers carefully consider the energy efficiency when } \\
\quad \text { determining to buy these appliances }\end{array}$ \\
\hline Frequent use & 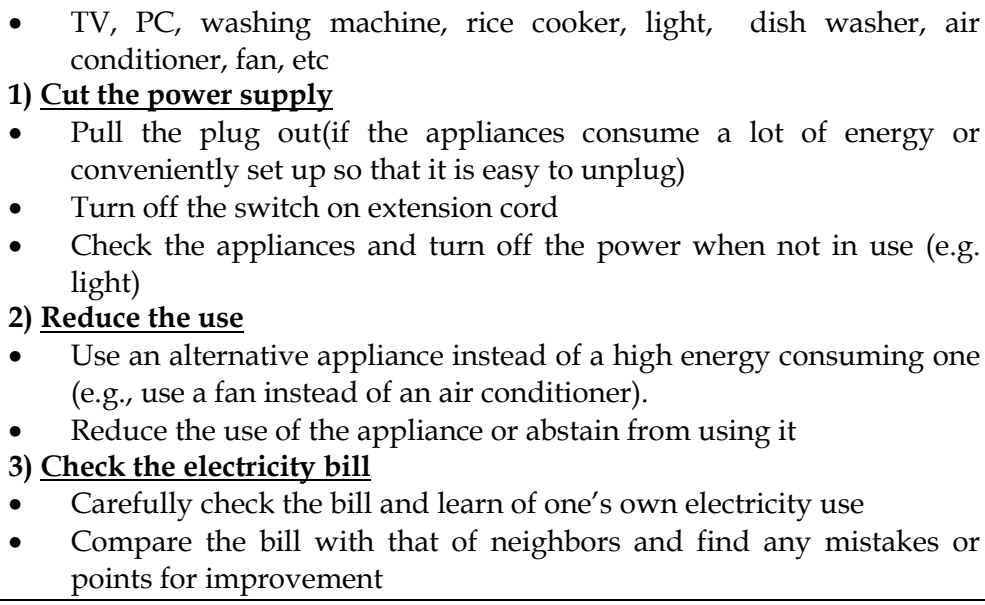 \\
\hline Occasional Use & $\begin{array}{l}\text { - Microwave, electric oven, hair dryer, video game console } \\
\text { - } \quad \text { Usually unplugged, for the safety and cleaner look of the house }\end{array}$ \\
\hline
\end{tabular}

Table 1. Consumers' attempted behaviors of saving the use of electricity

\begin{tabular}{|c|c|}
\hline Pain point & Unmet Needs \\
\hline Lack of functions & $\begin{array}{l}\text { - A function that blocks power leakage of unused appliances after } \\
\text { turning of the power } \\
\text { - A function that cuts the power supply of multiple appliances at once } \\
\text { - A timer function to control the use of electricity more conveniently }\end{array}$ \\
\hline $\begin{array}{l}\text { Lack of } \\
\text { Information }\end{array}$ & $\begin{array}{l}\text { - Information on the electricity usage level of each appliance and of } \\
\text { - } \\
\text { - Information on the level of energy-efficiency on each appliance } \\
\text { - Information on cumulative rate of electricity usage } \\
\text { - Information on efficient ways to reduce the use of electricity (e.g., } \\
\text { knowing which appliances can be operated on reduced energy and } \\
\text { which appliances consume electricity even when in not use) }\end{array}$ \\
\hline $\begin{array}{l}\text { Lack of } \\
\text { Motivator }\end{array}$ & $\begin{array}{l}\text { - A system that evaluates whether the efforts made in an attempt to } \\
\text { reduce the use of electricity have been effective and identifies the } \\
\text { effective ones } \\
\text { - } \quad \text { A motivator that stimulates consumers to reduce the use of electricity }\end{array}$ \\
\hline
\end{tabular}

Table 2. Unmet needs of saving use of electricity 


\subsection{Attitude towards the safe use of electricity}

Consumers were worried about the potential threats of using electricity and they engaged in activities geared toward the safe use of electricity. For example, some used products advertised as having the power to protect against harmful electromagnetic waves, such as stickers, coals and plants, while others paid closer attention to arranging appliances in a living room or kitchen to prevent electric shocks and some individuals even got into a habit of unplugging appliances in order to avoid short circuits.

\begin{tabular}{|l|ll|}
\hline Potential danger & \multicolumn{1}{|c|}{ Behaviors } \\
\hline $\begin{array}{l}\text { Harmful } \\
\text { electromagnetic } \\
\text { waves }\end{array}$ & $\begin{array}{l}\text { Attempt to prevent being exposed to harmful electromagnetic waves } \\
\text { - }\end{array}$ & $\begin{array}{l}\text { Appliances on watch-out list: devices that is used over a long period } \\
\text { of time like PC and TV or appliances with high emission of } \\
\text { electromagnetic waves like microwave }\end{array}$ \\
& $\begin{array}{l}\text { Attempted behaviors to thwart the potential danger: 1) use of } \\
\text { mediums advertised to block the harmful waves such as stickers, } \\
\text { coals and plants 2) avoid being too close to appliances emitting } \\
\text { harmful waves }\end{array}$ \\
\hline Electric Shock & - $\begin{array}{l}\text { Careful with uses of appliances placed in a bathroom or a kitchen } \\
\text { where they may get wet (e.g., hair dryer, bidet, etc) }\end{array}$ \\
\hline Short-circuit & $\begin{array}{l}\text { Attempted behaviors to thwart the potential danger: being careful } \\
\text { not to get appliances wet }\end{array}$ \\
\hline & $\begin{array}{l}\text { Fire or spark due to short circuit (caused by dusts on the outlet) } \\
\text { Consider the following as a potential danger: too many cords being } \\
\text { plugged in one outlet, twisted and complicated wiring } \\
\text { Attempted behaviors to thwart the potential danger: unplug cords } \\
\text { from outlet when leaving house }\end{array}$ \\
\hline
\end{tabular}

Table 3. Behaviors concerning the safe use of electricity

With regards to the safe use of electricity, all agreed with its importance but evaluated themselves as not adequately meeting the standard. All of the polled participants indicated that they agree or strongly agree with the importance of the safe use of electricity. However, only $66 \%$ agreed or strongly agreed that they are currently using electricity safely. Although the feeling of inadequacy was not as strong as it was in the energy reduction case (48\%), this data shows that consumers feel like they are not doing enough to prevent themselves from the potential danger of using electricity.

Although consumers constantly made an effort to protect themselves from the potential dangers of using electricity including harmful electromagnetic waves, electric shocks and short circuits, they still displayed a feeling of uneasiness. They pinpointed unmet needs in the following areas: device safeguards against the emission of harmful electromagnetic waves, a guide on how to safely handle appliances in bathrooms and in kitchens, and a device that automatically shuts off the power if there is a hazard.

\section{Directions for the provision of successful home services in a Smart Grid}

Our study shows that, in relation to saving electricity, consumers have unmet needs in the areas of 'functionality' in terms of aids for saving electricity. They also need 'information' that tells consumers about their usage behavior and 'motivation' that pushes consumers to 


\begin{tabular}{|l|l|}
\hline Pain point & \multicolumn{1}{|c|}{ Unmet Needs } \\
\hline $\begin{array}{l}\text { Danger of } \\
\text { electromagnetic } \\
\text { waves }\end{array}$ & $\begin{array}{l}\text { Needs to measure the level of emission of electromagnetic waves } \\
\text { by each appliance }\end{array}$ \\
\hline $\begin{array}{l}\text { Danger of } \\
\text { electric shock } \\
\text { electromagnetic waves }\end{array}$ & $\begin{array}{l}\text { Guide on how to safely handle electronic appliances, particularly } \\
\text { around water (e.g., in a bathroom or in a kitchen) }\end{array}$ \\
\hline $\begin{array}{l}\text { Danger of short } \\
\text { circuit }\end{array}$ & $\begin{array}{l}\text { A function that auto-cleanses outlet (e.g., extension cord with a } \\
\text { function of self-removing dusts) }\end{array}$ \\
\hline $\begin{array}{l}\text { A device/tool to organize convoluted wirings } \\
\text { A device that automatically shuts off the entire power when } \\
\text { leaving house }\end{array}$ \\
\hline
\end{tabular}

Table 4. Unmet needs in the areas of safe use of electricity

take actions. Also, in regards to the safe use of electricity, they have unmet needs in terms of protecting against electromagnetic waves, electric shocks and short circuits.

However, in order to provide a home service that satisfies the needs mentioned above, smart grid devices like a smart meter or a smart appliance must be connected to a home network system. Connecting a home network onto a smart grid opens the door for many new helpful services for consumers as a result of the positive synergy effect from combining electrical services with IT.

Suppliers simply need to know the total amount of electricity used in order to control their supply level. However, this information is not enough for consumers. In order to be an efficient electricity consumer, they need to know the level of usage for each appliance. Since each appliance consumes a different level of electricity, the total amount of electricity used after a given time can vary depending on the appliance. Many people may be aware of the fact that one air conditioner consumes the same amount of electricity required for operating thirty fans. However, not many may be aware of the fact that making a toast in an electronic oven consumes 33 times as much electricity as is required to make a toast in a toaster. If monitoring the electric usage of individual appliance becomes possible, consumers will save electricity by voluntarily using an appliance with a higher energy-efficiency level.

If a smart grid is connected to a home network system, consumers could reduce their electricity usage because appliances could be turned off automatically during peak electricity usage periods. Both consumers and suppliers could benefit from this, by increasing the generation efficiency. Consumers could use electricity at a lower rate and suppliers could reduce wasteful consumption during critical peak times when the demand is high.

There are various players in the business of providing home energy management systems that helps consumers to become better consumers of electricity. Google and Microsoft, two of the biggest IT corporations, recently launched their home energy management systems, called Google PowerMeter and MS Hohm, respectively. Their home energy management portals show the energy consumption of each home appliance, calculates the average electricity consumption of a consumer in real time, and provides consulting information on how to reduce energy consumption and $\mathrm{CO} 2$ emissions.

Combining a smart grid with a home network should proceed as a team effort including various players such as power suppliers, telecom companies, and electronic manufacturers. 
An open partnership between different players is crucial to foster the invention of converged smart services and to avoid overlapping capital investments.

There are various players in the business of providing home energy management systems that helps consumers to become better consumers of electricity. Google and Microsoft, two of the biggest IT corporations, recently launched their home energy management systems, called Google PowerMeter and MS Hohm, respectively. Their home energy management portals show the energy consumption of each home appliance, calculates the average electricity consumption of a consumer in real time, and provides consulting information on how to reduce energy consumption and $\mathrm{CO} 2$ emissions.

In addition to IT corporations, electrical power companies are also entering this business area. For example, General Electric (GE) has made smart appliances - devices that can take commands from utility companies or consumers to power down and save energy. Also, GE's consumer and industrial division has teamed up with Tendril to develop a system that will essentially allow utility companies employing Tendril's TREE (Tendril Residential Energy Ecosystem) platform to turn GE dryers, refrigerators, washing machines and other energy-gobbling appliances off or on to conserve power consumption.

Aside from their partnership with GE, Tendril also provides their own service as well. Tendril partners with utility companies and supplies smart meters, smart outlets and smart gateways to consumers. Consumers can remotely control each appliance at home using an iPhone or PC when a smart outlet is plugged in between a cord and an outlet. They can also shut down the power of less important appliances automatically during peak times.

Combining a smart grid with a home network should proceed as a team effort including various players such as power suppliers, telecom companies, and electronic manufacturers. An open partnership between different players is crucial to foster the invention of converged smart services and to avoid overlapping capital investments.

\section{Suggestion for a Smart Green Service and the willingness to use it}

\subsection{Service concept}

Based on the result of our earlier study, we developed a service called the 'Smart Green Service' with four distinct functions as shown in Table 5. As illustrated in Figure 5, the Smart Green Service allows an individual to discover their total amount of electric usage for individual appliances by setting up a 'Smart box' and 'Smart Tags' at home.

A Smart Box gathers the data of electrical devices from some Smart Tags inside the house and the household electricity usage from Smart Meters via ZigBee or PLC, and sends the data to the SGC (Smart Green Center). In addition, the Smart Box receives control messages from the center through Ethernet, and transmits them to the Smart Tags, thus acting as a gateway. A Smart Tag monitors and controls the power usage of each electrical device. The measurement is conducted by placing the Smart Tag between an outlet and an electrical device which monitors its electricity usage with a CT (Current Transformer) sensor. The measured data is transmitted to a Smart Box through ZigBee or PLC. In addition, the Smart Tag embedded with an actuator is possible to be powered on or off according to commands from the Smart Box. Figure 6 illustrate Smart Box and Smart Tag.

A Smart Meter measures the household electricity usage and sends the data to the SGC or a Smart Box via any networking module. Generally, it receives control commands from the SGC, and passes them to Tags or Boxes. However, the smart meter in the KT Smart Green Service is not able to receive and to pass on the commands so the command handling function is taken over by the Smart Box. 


\begin{tabular}{|l|l|}
\hline $\begin{array}{l}\text { Energy } \\
\text { Senitoring }\end{array}$ & $\begin{array}{l}\text { This service monitors the total energy usage and the energy usage of each } \\
\text { appliance in real time using a PC, SoIP 3, IPTV and mobile phone. } \\
\text { Consumers can monitor their electricity usage/rate and } \mathrm{CO}_{2} \text { emissions } \\
\text { and get notified before a higher cumulative rate is applied. }\end{array}$ \\
\hline $\begin{array}{l}\text { Standby Power } \\
\text { Cut Service }\end{array}$ & $\begin{array}{l}\text { This service helps consumers to save electricity by automatically cutting } \\
\text { off standby power when a smart tagged appliance is on standby. } \\
\text { Consumers can choose various settings such as 'out' 'bedtime', etc. so } \\
\text { that for example, when a consumer chooses the 'out' setting, the standby } \\
\text { power on appliances can be cut off. }\end{array}$ \\
\hline $\begin{array}{l}\text { Remote Control } \\
\text { Service }\end{array}$ & $\begin{array}{l}\text { This service lets consumers control their smart tagged home appliances } \\
\text { remotely via PC, SoIP, IPTV or mobile phone. }\end{array}$ \\
\hline $\begin{array}{l}\text { Energy } \\
\text { Sonsulting }\end{array}$ & $\begin{array}{l}\text { This service provides customized consulting services to consumers, } \\
\text { based on a careful analysis of their electricity usage via e-mail, mobile }\end{array}$ \\
\hline
\end{tabular}

Table 5. The functions of Smart Green Service

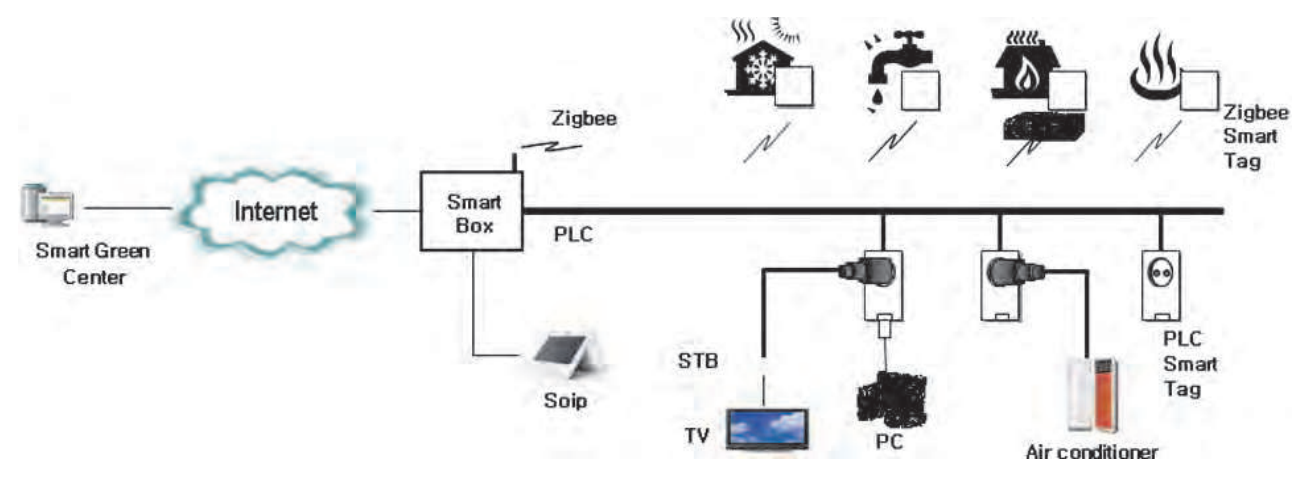

Fig. 5. Components of the Smart Green Service
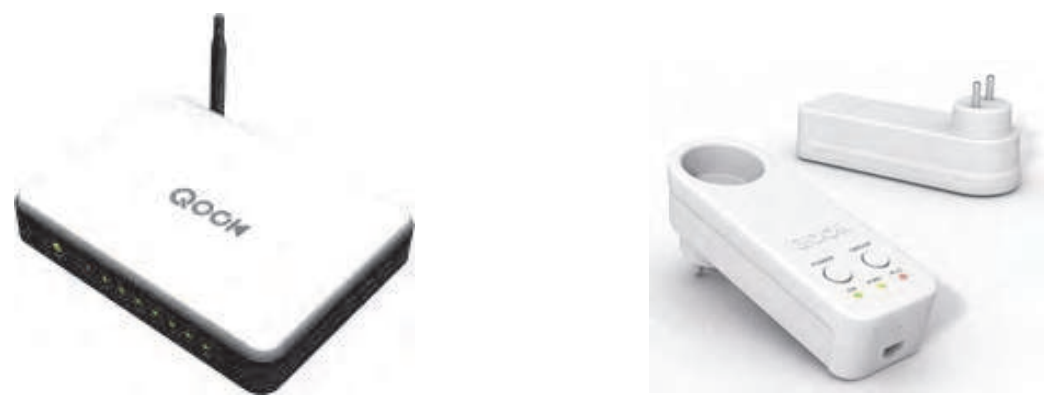

Fig. 6. Smart Box (left) and Smart Tag (right)

\footnotetext{
${ }^{3}$ SoIP (Service over IP) is an advanced VoIP(voice over IP) system that has many functions like call, videophone, SMS, e-banking and searching via IP.
} 
The SGC are mainly divided into the management system monitoring Smart Boxes/Tags, the application server system providing customer services, and data warehouse system maintaining data for managing network elements and providing services. The center handles and stores metered and measured data, analyze electric usage in various time intervals (hourly, daily, monthly or annually) and by categories such as neighborhood, region, and living standard. Not only system operators but also customers can determine statistical results, and set commands to control their electricity usage automatically.

KT (Korea Telecom) already made Smart Box and Smart Tag prototypes and will participate in the Jeju Smart Grid Demonstration Project from 2010 to 2013 in order to test and improve the equipment. The Jeju Smart Grid Demonstration Project is a vast project that tests stateof-the-art smart grid technology in five different fields - smart place, smart transport, smart renewable energy, smart electricity service and smart power grid. Over 150 companies will participate in the project, testing 6000 homes over the next four years.

\subsection{Service evaluation (by qualitative survey)}

Participants evaluated the Energy Monitoring Service positively for the following reasons: By informing them of the exact amount of electricity usage on each device, their curiosity is satisfied, they are more motivated and better strategized. However, some suggested that too detailed information may be a cause of stress. They also made additional suggestions such as an alarming function that rings when a child touches an outlet, a system that notes the amount of electromagnetic waves emitted by each appliances and a service that sends out a text message in case of electric outage.

Participants evaluated Standby Power Cut Service positively for the fact that it removes them of hassles to unplug. However, willingness to pay for the service was much lower because they could not see a distinct benefit of using the service apart from using an extension cord.

Although Remote Control Service received some positive feedback for aiding safe use of electricity by removing threats of potential danger, overall, participants showed very low willingness to pay for the service since they considered the occasions to use such service to be very rare. Additionally, they showed needs for a service that also controls the power of lights, not just the smart tagged appliances, and for a service that notifies when a person uses electricity via mobile service.

Participants showed interested in immediate and professional problem solving Energy Consulting Service can provide, but they considered such service to be going overboard and worried that it may be a cause of stress. However, they showed needs for consulting service via online chatting and online portal where they can share information on using electricity.

\subsection{Willingness to use suggested services (by quantitative survey)}

As shown in Table 6, all four of the Smart Green Services offerings got a high willingness-touse rating of over $60 \%$, showing that consumers are highly interested in home-based electricity services.

Among the four services, the Energy Monitoring and Standby Power Cut Service received the highest willingness-to-use ratings, $78.3 \%$ and $76.3 \%$, respectively. The Remote Control Service and the Energy Consulting Service received a lower, but still high willingness-to-use rating, $64.7 \%$ and $60.3 \%$, respectively. 


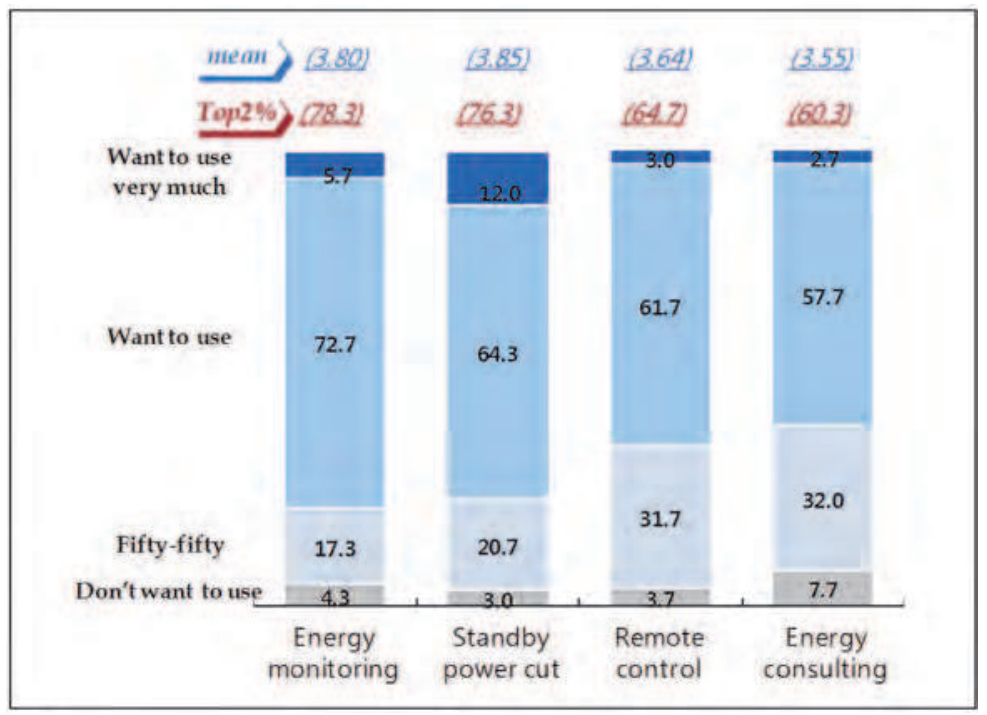

Table 6. Willingness to use

As shown in Table 7, participants who chose no willingness-to-use did not want to use the service because they expected the service to be difficult and complex to use and ineffective for saving energy. They thought the Energy Consulting Service would be particularly difficult and complex to use. They also had doubts about the Remote Control Service; they did not think that the service could actually work smoothly.

\begin{tabular}{|c|c|}
\hline Reasons & Services \\
\hline It seems too difficult to understand and use & 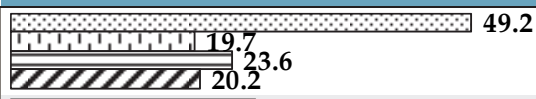 \\
\hline It's not useful for saving energy and money & 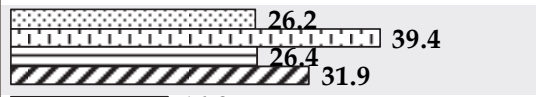 \\
\hline $\begin{array}{l}\text { It's not useful for using electricity safely and } \\
\text { conveniently }\end{array}$ & $\frac{16.9}{\operatorname{Cl} 17.9}$ \\
\hline $\begin{array}{r}\text { It's not necessary, I'm already using similar } \\
\text { services }\end{array}$ & $\begin{array}{l}4.6 \\
1,117 \\
=3.4\end{array}$ \\
\hline I'm not interested in such services & $\begin{array}{l}0.0 \\
2.8 \\
0.9 \\
0.8\end{array}$ \\
\hline I can't trust it work well, safely & 28.3 \\
\hline $\begin{array}{r}\text { It's so annoying and complicated so I'll not } \\
\text { use those services }\end{array}$ & 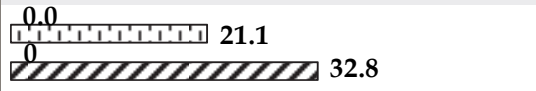 \\
\hline
\end{tabular}

Energy monitoring 回 Standby power cut 目 Remote control $\square$ Energy consulting

Table 7. The reasons for not wanting to use the service 


\section{Conclusion}

In this study, we have explored consumers' perceptions and attitudes toward using electricity by observing their behavior using HV and we studied a cognitive map derived from a FGD model. Based on the result, we have developed smart grid home services and tested consumers' willingness to use our services using a survey.

Consumers perceived electricity as an indispensable necessity that makes the use of home appliances easier and they wanted electricity saving activities to be both easier-tounderstand and stress-free, and also wanted to use electricity safely without being exposed to the potential dangers of using electricity such as harmful electromagnetic waves, short circuits and electric shocks.

Consumers made varied efforts to be aware of their electricity usage in order to reduce their electricity usage; they unplugged appliances that are occasionally used like TVs or PCs, thoroughly studied electricity bills and compared them with that of their neighbors. However, they found that conserving electricity is difficult due to a lack of functionality, information and motivation. They showed unmet needs in the following areas: a function that cuts off standby power, a function that informs the user of the level of electricity usage and the energy efficiency of each device, an alarm that notifies the user of changes in the electricity rate, and a motivation system that pushes consumers to conserve electricity.

Consumers were also taking various steps to protect themselves from the potential threats of using electricity. However they still felt uneasy about safety. In terms of the safe use of electricity, they showed unmet needs in the following areas: the need for a simple device that protects against harmful electromagnetic waves, a guide on how to safely handle electronic appliances in a bathroom and a kitchen and a function that shuts off the entire power supply.

To satisfy the unmet needs in the aforementioned areas, KT has developed Smart Green Services that can monitor the aggregated and individual electricity consumption rate of consumers in real time using a smart box and tag. All four services received a high willingness to use rating of over $60 \%$.

KT will participate in the Jeju Smart Grid Demonstration Project from 2010 to 2013 and test prototype equipment examples - like the smart box and tag - that are enabled with services like Energy Monitoring and Remote Control.

When our Smart Green Service, which was developed based on consumers' opinions and unmet needs, integrates several technical innovations and gets the active participation of consumers, it will come closer to the ultimate goal of a smart grid, allowing the efficient use of electricity.

\section{References}

Lee, H. \& Park, H. (2009), To Estabilish Smart Grid Roadmap, pp. 139-154, Ministry of Knowledge Economy, Seoul, Korea, pp.139-154

Kim, M. (2009), The estabilishment of Korean smart grid, TechnologyManagement, August 2009, pp. 36-41

Moon, S. (unpublished), Green economy and Smart Grid, Seoul National University, Seoul, Korea

Haaser, B. (2008), Connecting Smart Homes and Smart Grids to Save Energy, LonmarkMagazine, Vol. 4, Issue 3, 2008, pp. 20-23 
Leeds, D. (2009), The smart grid in 2010: Market segments, applications and industry players, GTM research

John, J. (2009), Microsoft Hohm: First Seattle City Light, Now Xcel Energy, Greentech Media Kanellos, M. (2009), GE, Tendril Team Up on Smart Home Technology, Greentech Media John, J. (2009), Top Ten Smart Grid, Greentech Media

Kanellos, M. (2009), Tendril Targets Meter Makers, Greentech Media

http://www.tendrilinc.com/consumers/products/ 


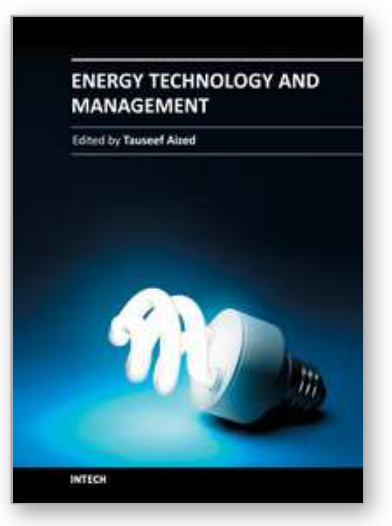

\author{
Energy Technology and Management \\ Edited by Prof. Tauseef Aized
}

ISBN 978-953-307-742-0

Hard cover, 228 pages

Publisher InTech

Published online 30, September, 2011

Published in print edition September, 2011

The civilization of present age is predominantly dependent on energy resources and their utilization. Almost every human activity in todayâ $€^{\mathrm{TM}} \mathrm{S}$ life needs one or other form of energy. As worldâ $€^{\mathrm{TM}} \mathrm{s}$ energy resources are not unlimited, it is extremely important to use energy efficiently. Both energy related technological issues and policy and planning paradigms are highly needed to effectively exploit and utilize energy resources. This book covers topics, ranging from technology to policy, relevant to efficient energy utilization. Those academic and practitioners who have background knowledge of energy issues can take benefit from this book.

\title{
How to reference
}

In order to correctly reference this scholarly work, feel free to copy and paste the following:

Young-Myoung Kim and Young-Woo Lee (2011). Smart Home Services for a Smart Grid, Energy Technology and Management, Prof. Tauseef Aized (Ed.), ISBN: 978-953-307-742-0, InTech, Available from:

http://www.intechopen.com/books/energy-technology-and-management/smart-home-services-for-a-smart-grid

\section{INTECH}

open science | open minds

\author{
InTech Europe \\ University Campus STeP Ri \\ Slavka Krautzeka 83/A \\ 51000 Rijeka, Croatia \\ Phone: +385 (51) 770447 \\ Fax: +385 (51) 686166 \\ www.intechopen.com
}

\author{
InTech China \\ Unit 405, Office Block, Hotel Equatorial Shanghai \\ No.65, Yan An Road (West), Shanghai, 200040, China \\ 中国上海市延安西路65号上海国际贵都大饭店办公楼 405 单元 \\ Phone: +86-21-62489820 \\ Fax: $+86-21-62489821$
}


(C) 2011 The Author(s). Licensee IntechOpen. This chapter is distributed under the terms of the Creative Commons Attribution-NonCommercialShareAlike-3.0 License, which permits use, distribution and reproduction for non-commercial purposes, provided the original is properly cited and derivative works building on this content are distributed under the same license. 